\title{
COSMOPOLITISMO E DIREITOS COMO DESAFIOS CONTEMPORÂNEOS
}

\author{
FRANCISCO URIBAM XAVIER DE HOLANDA \\ Licenciado em Filosofia Política, doutor em Sociologia e \\ professor do Departamento de Ciências Sociais da UFC.
}

Ficam aqui registrados meus agradecimentos a Maju Miranda, minha primeira leitora, cujas valiosas sugestões ajudaram a melhorar o texto.

Resumo: A tensão entre regulação social e emancipação social evidencia, para Boaventura, que a promessa moderna de articulação dialética, que combina regulação e emancipação, ou seja, a articulação entre ordem e progresso no capitalismo, não pode ser cumprida. A Emancipação deixou de ser o outro da regulação e o que temos é um amplo processo de regulação da sociedade que se efetiva por meio da degradação do Estado-Providência e pelo avanço de uma agenda neoliberal, que reduzem direitos e ampliam o processo de exploração do mercado em escala global. Palavras-chave: Política. Direitos. Emancipação. Regulação. Globalismos.

O presente texto é uma apresentação descritiva e reflexiva sobre alguns conceitos desenvolvidos por Boaventura de Sousa Santos, sociólogo português que vem nos propondo pensar a superação ou ruptura em relação à visão iluminista e eurocêntrica a partir do que ele denomina de epistemologias do Sul. Epistemologias que podem ser efetivadas por meio de uma ecologia de saberes. Os conceitos apresentados aqui são da leva de reflexões que Boaventura elaborou durante a última década do século $\mathrm{XX}$, quando preparou os fundamentos para formulação da metáfora das epistemologias do Sul ${ }^{1}$.

1 "Designamos a diversidade epistemológica por epistemologias do Sul. O Sul é aqui concebido metaforicamente como um campo de desafios epistêmicos que procuram 
Para Boaventura, o projeto de modernidade ocidental vulgarmente é chamado de sistema capitalista, ocultando, assim, sua base epistemológica: o padrão científico de produzir e legitimar o conhecimento chegou, em meados do século XX, marcado por três tensões: a primeira, entre regulação social e emancipação social; a segunda, entre Estado e Sociedade; e a terceira, entre Estado-Nação e Globalização [SANTOS, 1997]. Para ele:

O projeto da modernidade é caracterizado, em sua matriz, por um equilíbrio entre regulação e emancipação, convertidos nos dois pilares sobre os quais se sustenta a transformação radical da sociedade prémoderna. O pilar da regulação é constituído por três princípios: o princípio do Estado [Hobbes], o princípio do mercado [Locke] e o princípio da comunidade [Rousseau]. O pilar da emancipação é constituído pela articulação entre três dimensões da racionalização e secularização da vida coletiva: a racionalidade moral-prática do direito moderno; a racionalidade cogntivo-experimental da ciência e da técnica modernas; e a racionalidade estético-expressiva das artes e da literatura moderna. O equilíbrio pretendido entre a regulação e a emancipação obtém-se pelo desenvolvimento harmonioso de cada um dos pilares e das relações dinâmicas entre eles [SANTOS, 1995, p. 236].

A tensão entre regulação social e emancipação social evidencia, para Boaventura, que a promessa moderna de articulação dialética, que combina regulação e emancipação, ou seja, a articulação entre "ordem e progresso" no capitalismo, não pode ser cumprida. A Emancipação deixou de ser o outro da regulação e o que temos é um amplo processo de regulação da sociedade que se efetiva por meio da degradação do Estado-Providência e pelo avanço de uma agenda neoliberal que reduzem direitos e ampliam o processo de exploração do mercado em escala global. A crise de regulação é simbolizada pela incapacidade do capitalismo de manter o Estado do bemestar social como manteve, temporariamente, em alguns países da Europa, nos Estados Unidos e Canadá. Já a crise de emancipação é simbolizada, nos

reparar os danos e impactos historicamente causados pelo capitalismo na sua relação colonial com o mundo... A ideia central é que o colonialismo, para além de todas as dominações porque é conhecido, foi também uma dominação epistemológica, uma relação extremamente desigual de saber-poder que conduziu à supressão de saber próprios dos povos e/ou nações colonizadas. As epistemologias do Sul são o conjunto de intervenções epistemológicas que denunciam essa supressão, valorizam os saberes que resistiram com êxito e investigam as condições de dialogo horizontal entre conhecimentos. A esse diálogo entre saberes chamamos de ecologia de saberes [SANTOS, 2010, p.19].” 
limites da racionalidade moderna, pelo colapso do socialismo real e pela crise de revolução social a partir do pensamento crítico de matriz moderna, entre eles, o marxismo. Diz Boaventura:

Marx acreditou, sem reservas, no desenvolvimento neutro e infinito
das forças produtivas, no progresso como processo de racionalização
científica e técnica da vida, na exploração sem limites da natureza para
atender às necessidades de uma sociedade de abundância para todos.
Em suma, a utopia de Marx é, em tudo, um produto da modernidade
e, nessa medida, não é suficientemente radical para nos guiar num
período de transição paradigmático $[1995$, p. 3].

A tensão entre o Estado e a sociedade refere-se à sociedade civil pensada enquanto o outro do Estado, com capacidade de se autorreproduzir por meio de mecanismos, como leis e regulações, que podem democratizar o Estado na medida em que se possa ter garantias jurídicas para o respeito às leis e às regulamentações. Nessa perspectiva, se os direitos humanos [direitos civis e políticos] foram conquistados em uma luta da sociedade civil contra os abusos do próprio Estado, este é considerado um dos principais violadores dos direitos humanos. Já os direitos econômicos, sociais e culturais foram conquistados pressupondo o Estado como o seu principal garantidor. E são, exatamente, esses direitos que passaram a ser negados pela onda de reformas neoliberais que, desde a década de 70 do século passado, vêm se impondo no planeta como solução para crise econômica de reprodução do capital em escala global.

A tensão entre Estado-Nação e globalização refere-se à crise do modelo político da modernidade ocidental, formado por Estado-Nação soberano, que constitui um sistema interestatal. Nesse sistema, o EstadoNação [país] é a unidade que articula, no projeto de modernidade, tanto a promessa de regulação como a de emancipação. Com o fim da Guerra Fria, a intensificação do processo de globalização vem promovendo a erosão do poder do Estado-Nação, fazendo com que os países, principalmente os periféricos, percam a sua esperança de definir os rumos do seu processo de desenvolvimento, ou seja, o processo de globalização coloca os países diante da impossibilidade de serem agentes da regulação e da emancipação. Nesse contexto, vem a questão: a regulação e a emancipação deverão ser deslocadas para o nível global? Para o cosmopolitismo? Como regular a ação do capital global, ou seja, de um capital que não tem mais nacionalidade? Qual a função da política em um mundo global? 
$\mathrm{Na}$ situação de sociedades pobres e emergentes [Brasil, México, Argentina, Portugal, Itália, Taiwan, Colômbia, Espanha, Grécia, Coreia, Índia], existem problemas modernos para serem resolvidos, mas não existem mais as condições para resolvê-los nos termos modernos. Essas sociedades precisam de estado providência, mas não há condições para se criá-lo no modelo que vigorou na Europa no pós-guerra; precisam de mais direitos, mas não podem ser criados como foram criados no período da modernidade; elas têm problemas modernos para resolver, como justiça, igualdade, liberdade, cidadania e democracia, mas são problemas para os quais, hoje, não há solução em termos modernos. Para Boaventura, os países periféricos precisam encontrar novas formas de organização da sociedade civil, precisam inventar o Estado, precisam criar novas formas de constituição da sociedade, se querem realizar as promessas da modernidade não realizadas no período em que elas foram realizadas nos países que compõem o centro do capitalismo.

Os países periféricos, pobres e emergentes são sociedades complexas na sua dualidade estrutural: são sociedades de primeiro mundo em certos aspectos e do terceiro mundo em outros. Atualmente, a relação e a diferenciação entre países ricos e pobres são de difícil caracterização, pois nossos instrumentos analíticos foram constituídos com base em sociedades nacionais e o mundo está se globalizando. A questão da globalização é um desafio para o qual as ciências sociais não estão equipadas para compreender e lançar luzes, mesmo para tradição sociológica crítica marxista em que a globalização esteve presente, pois o marxismo via o capitalismo enquanto uma ordem mundial permanente. Por exemplo, o fato de que a teoria marxista previa que os trabalhadores do mundo inteiro se uniriam contra o capitalismo. Marx chega a dizer que a classe trabalhadora seria o coveiro do capitalismo, mas quem se uniu foi o capital. Os trabalhadores estão cada vez mais fragmentados e isolados em seus espaços. Aqui, no Brasil, a reforma trabalhista de Michel Temer, cujo processo de aprovação se concluiu no dia 11 de julho de 2017, não teve mobilização e pressão por parte das organizações dos trabalhadores. A reforma trabalhista altera mais de cem pontos da CLT, permitindo, entre outras coisas, o parcelamento de férias em até três vezes, a contratação de terceirizados para atividades fins e o trabalho por pagamento por hora, em regime intermitente.

Para Boaventura, diante da crise da modernidade, temos que repensar nossos instrumentos analíticos para darmos conta do que é o processo de 
globalização. Globalização tem muito haver com mudanças nas estruturas que atingem o Estado, a política, a cultura. Para ele, não se trata de globalização, mas sim, de globalizações. Globalização é um conjunto de relações sociais; sendo diferentes as relações sociais, diferentes são as globalizações. Portanto, ao falamos de processo de globalização, devemos falar sempre no plural, porque elas não são, nem sociologicamente nem politicamente, do mesmo tipo.

A globalização é muito difícil de definir. Muitas definições centramse na economia, ou seja, na nova economia mundial que emergiu nas últimas duas décadas como consequência da intensificação dramática da transnacionalização da produção de bens e serviços e dos mercados financeiros - um processo através do qual as empresas multinacionais ascenderam a uma preeminência sem precedentes como actores internacionais. Para os meus objetivos analíticos privilegio, no entanto, uma definição de globalização mais sensível às dimensões sociais, políticas e culturais. Aquilo que habitualmente designamos por globalização são, de fato, conjuntos diferenciados de relações sociais; diferentes conjuntos de relações sociais dão origem a diferentes fenômenos de globalização. Nestes termos, não existe estritamente uma entidade única chamada globalização; existem, em vez disto, globalizações; em rigor, este termo só deveria ser usado no plural. Qualquer conceito mais abrangente deve ser do tipo processual e não substantivo. Por outro lado, enquanto feixes de relações sociais, as globalizações envolvem conflitos e, por isso, vencedores e vencidos. Freqüentemente, o discurso sobre globalização é a história dos vencedores contada pelos próprios. $\mathrm{Na}$ verdade, a vitória é aparentemente tão absoluta que os derrotados acabam por desaparecer totalmente da cena [SANTOS, 1997, p. 107].

Além de afirmar que o termo globalização deveria ser usado no plural, Boaventura afirma que não há globalização autêntica. Para ele, o que denominamos globalização é normalmente a globalização de uma condição local que se amplia criando um processo de mundialização. Assim, é muito importante que possamos identificar o ponto de partida, ou seja, a localização, pois globalização faz par com localização. Por exemplo, quando se globaliza uma condição social, isso acontece por meio de processo mediante o qual uma condição local se expande criando rivalidades com outras condições locais. A língua inglesa é uma língua global? Não. É uma língua de certos países: Inglaterra, Estados Unidos e alguns países da África e da Ásia. E, então, por que ela é considera uma língua global atualmente? Porque ela se expandiu localizando outras: a francesa, a portuguesa, o espanhol. 
No processo de colonização, a Espanha expandiu sua língua localizando as várias línguas faladas pelas populações originárias. Portanto, quando algo se globaliza [universaliza], produz a localização [invisibilidade, anulação, perda de importância] de algo que lhe é rival.

Todo processo de globalização de uma determinada atividade localiza outra. A globalização da Coca-Cola e do Mcdonald's localiza a boa comida do Ceará, de Portugal, da África, e tantos outros lugares, que são bem melhores. Se a globalização faz par com a localização, o que se globaliza são produtos, serviços e modos de vida, pois os grupos sociais que contribuem para globalização, em si mesmos, estão confinados e localizados mais do que nunca. Os camponeses do Peru, Bolívia e Equador, que contribuem para a cultura global do uso da coca e para produção de minérios, continuam, enquanto grupos sociais, presos às suas aldeias e montanhas como estavam há 500 anos. Portanto, podemos estar dentro de um sistema global, mas localizados. Podemos ter relações globais por meio das redes sociais.

No mundo do trabalho, defrontamo-nos com a globalização dos processos produtivos, fruto da revolução do conhecimento nas áreas de microeletrônica, da nanotecnologia, das telecomunicações, da informática e dos transportes. Todavia, se a produção é globalizada, os mercados de trabalho são fragmentados. Um técnico de computação nas Filipinas ganha um quarto do que ganha o mesmo técnico na Holanda, com as mesmas competências, com os mesmos cursos, eventualmente, formado na mesma universidade. É buscando baratear o custo do valor do trabalho que as empresas transferem sua contabilidade e parte do processo produtivo para os países periféricos, pois podem produzir neles, com a mesma tecnologia e a mesma qualidade, mas com preços mais baratos e até com exploração de mão de obra em regime de semiescravidão. Portanto, globalização também faz par com a segmentação, não há homogeneização, mas segmentação social.

O fenômeno da segmentação resgata a questão da identidade e do reconhecimento, porque os que estão localizados, trabalhadores, povos indígenas, afrodescendentes e tantos outros, precisam entender qual sua identidade, precisam de reconhecimento. Em todas as partes do mundo, assistimos a emergência de grupos sociais que reivindicam sua identidade ou buscam reconhecimento, são as mulheres, os negros, os gays, os povos 
indígenas, os refugiados, os migrantes. Trata-se de movimentos que se configuram como tentativas de afirmação de suas raízes ou de criar raízes em um mundo que não está sendo organizado segundo as suas raízes [identidade], mas de acordo com opções [lógica de mercado, da diferença].

Para Boaventura, na medida em que a sociedade parece dar opções sem limites, os grupos sociais procuram raízes. A divisão da modernidade entre opções e raízes configura uma dicotomia. Pensamento de raízes é o pensamento de tudo que é profundo, permanente, único, singular, de tudo que dá segurança e consistência. Pensamento de opções é o pensamento de tudo que é variável, efêmero, substituível, possível, indeterminável. Todo pensamento científico, toda análise sociológica, antropológica, política, econômica e psicanalítica é constituída pela dicotomia entre raízes e opções. Qual é, no fundo, no marxismo, a distinção entre base e superestrutura? A base é a raiz e a superestrutura é a opção. Qual a distinção, em Freud, entre id, ego e superego? O id é a raiz; o ego e o superego, opções.

A cultura moderna foi toda idealizada em uma relação dinâmica entre raízes e opções. A globalização é uma maneira de trabalhar esta dicotomia. Todavia, com a massificação dos serviços de internet, ou seja, com a popularização do uso do espaço eletrônico [ciberespaço], a dicotomia raízes e opções passou a entrar em colapso, pois, na internet, as pessoas poderiam optar por ser negras, brancas, índios, bissexuais, homossexual, lésbicas, constatando-se que se poderia optar por qualquer maneira de ser. Tal possibilidade passou a gerar problemas para nós modernos, que fomos habituados a pensar a partir da grande raiz da modernidade. A maneira de ser e de estar no mundo da modernidade é por meio da criação de raízes que fundamentam opções. A raiz da modernidade é o conceito de razão do iluminismo. É uma raiz que se firma pelo modo que cria opções pela razão, assim, os indivíduos têm mais opções, pois a razão se coloca como a raiz que legitima a estrutura que determina as opções.

Diante desde contexto, diz Boaventura, devemos estar atentos ao chamado pós-modernismo celebratório que, diante da crise da modernidade, afirma não existir mais metanarrativas ${ }^{2}$, não haver mais utopia, que chegamos

\footnotetext{
2 Metanarrativas são pressupostos de saber que proclamam a existência de verdades universais ou absolutas que fundamentam e legitimam projetos científicos ou políticos. Exemplos de metanarrativas: a criação de riquezas e prosperidades para todos por meio
} 
ao fim da história, que não há mais sujeito transformador da história, que não há mais pelo que optar, que as mudanças são de cunho individual. Todavia, nunca foi tão importante optar, nuca foi tão importante os cientistas sociais saberem de que lado se colocar, porque nunca foi tão difícil saber exatamente quais os processos sociais em que se criam uns e outros.

Os modelos de globalização, para Boaventura, não têm a mesma lógica, são diferentes e temos que analisá-los em suas diferenças. Partindo da definição de que não há um processo de globalização genuíno, que globalização é um processo no qual uma condição local se mundializa e, ao fazê-lo, adquire a capacidade de designar as condições rivais como locais, sabendo, ainda, que globalização não é homogeneização, mas segmentações, podemos distinguir quatro grandes modelos de globalização:

Primeiro, os localismos globalizados, que são os processos ligados à dinâmica de acumulação do capital por meio do qual os países, as sociedades e os processos econômicos locais adquirem suas dinâmicas. Toda produção industrial [fordismo, taylorismo, toyotismo] é um localismo globalizado. O modelo neoliberal é um localismo globalizado, ele tem origem no capitalismo central [nglaterra e Estados Unidos] e seus conceitos e receitas são impostos em escala planetária.

Segundo, os globalismos localizados, que são os impactos específicos dos localismos globalizados em países que o executam. Por exemplo, em alguns dos portos de países da África Ocidental, encontraremos parte deles fechados com grandes quantidades de contêineres de lixo tóxico que os países tiveram que importar ou comprar para abater parte da dívida externa contraída com os países centrais produtores de lixo tóxico. No Brasil, agrotóxicos, cujo uso é proibido nos países centrais, continuam sendo produzidos lá e vendidos e utilizados em larga escala na nossa agricultura.

da propriedade privada num regime de livre mercado [Teoria Liberal de Adam Smith]; emancipação da humanidade por meio da revolução proletária [Materialismo Histórico de Karl Marx]; a teoria da origem das espécies a partir da seleção natural [Teoria de Charles Darwin]; teoria da compreensão do inconsciente [Teoria da psicanálise de Sigmund Freud]. Estas são metanarrativas modernas, mantidas pela crença de que a razão iluminista, efetivada como ciência, pode dominar e explicar toda e qualquer realidade. Jean-François Lyotard definiu a condição pós-moderna como o fim ou o ceticismo em relação a todas as metanarrativas. Todavia, o que alguns pós-modernos acabam esquecendo é que a sociedade de mercado neoliberal é uma metanarrativa. 
Todas as zonas de livre comércio são exemplos de globalismos localizados. O desemprego estrutural é outro exemplo. Para Boaventura [1997], os países periféricos e semiperiféricos se especializaram em globalismos localizados, enquanto os países centrais se especializaram em localismos globalizados.

Terceiro, os cosmopolitismos, que são os processos de globalização de lutas localizadas. São formas de globalização insurgentes que não se submetem à lógica do capital. É a globalização da luta, da cidadania, são os grupos oprimidos que estão procurando mundializar a cidadania e sua indignação política. Por exemplo, os grupos indígenas ligados entre si, as redes de ativistas e movimentos ecológicos, as redes internacionais de direitos humanos, a articulação mundial em defesa dos refugiados, os protestos paralelos aos encontros em Davos, o fórum social mundial e a articulação sindical entre o Mercado Comum Europeu e o Mercosul.

Quarto, a herança comum da humanidade, em que há certas entidades e condições naturais [lua, fundos dos mares, Antártida] que pareciam ser patrimônio da humanidade, mas que vêm sofrendo tentativas de apropriação por parte de alguns países centrais, numa verdadeira estratégia geopolítica. Existe em curso uma luta de grupos ecológicos, junto a setores das Nações Unidas, para identificar certas realidades naturais no mundo que não podem ser apropriados por nenhum país, nenhuma empresa ou por alguém. Essa é uma luta importante, pois nós não temos conceito de propriedade global. A propriedade é grupal ou individual, mas o conceito de algo impropriado nós não temos.

A luta hoje pela propriedade da lua é muito grande entre Estados Unidos e Rússia. Os países periféricos dizem que a lua é propriedade da humanidade, já os países centrais dizem que não. Essa disputa é em função da presença do combustível "Isótopo Hélio 3" que, segundo pesquisa, será o combustível dos séculos XXI e XXII. Atualmente, já é mais barato trazê-lo da lua para uso na terra. Os russos dizem quem vão começar a transportá-lo em 2020. Todavia, especialistas dizem que isso não vai acontecer enquanto não se esgotar o uso do petróleo, por conta dos arranjos geopolíticos no mundo, pois se o petróleo perder sua importância, não é só ele que se acaba, mas toda uma ordenação geopolítica que ajuda a manter um padrão mundial de poder vigente, o que pode gerar guerras capazes de fazer desaparecer partes do mundo. A apropriação e o controle do "Isótopo Hélio 3" significa 
a possibilidade de dominação do mundo. Portanto, a lua é patrimônio da humanidade ou de alguns países que têm tecnologia para explorá-la?

O desafio, para quem quer pensar de forma crítica a crise da modernidade, é pensar o global de par com o local. E esclarece Boaventura que a utopia realista do século XXI é ecológica e democrática. Diz ele:

A utopia ecológica é utópica, porque a sua realização pressupõe a transformação global, não só dos modos de produção, mas também do conhecimento científico, dos quadros de vida, das formas de sociabilidade e dos universais simbólicos e pressupõe, acima de tudo, uma nova relação paradigmática com a natureza, que substitua a paradigmática moderna. É uma utopia democrática porque a transformação a que aspira pressupõe a repolitização da realidade e o exercício radical da cidadania individual e coletiva, incluindo nela a carta dos direitos humanos da natureza. É uma utopia caótica porque não tem um sujeito histórico privilegiado. Os seus protagonistas são todos os que, nas diferentes constelações de poder que constituem as práticas sociais, têm consciência de que a sua vida é mais condicionada pelo poder que os outros exercem sobre eles do que pelo poder que exercem sobre outrem [1995, p. 43-44].

Para que possa se intensificar um movimento de interrupção que rivalize com o projeto civilizador da modernidade, para rompermos com o capitalismo e o modo de vida que ele impõe ao planeta, diz Boaventura que é preciso "des-pensar muito do que até agora foi pensado como sento certo e perene, sobretudo do Norte Global [Europa e América do Norte]". O primeiro des-pensamento consiste na compreensão de que a realidade do mundo é mais ampla e diversa do que a visão ocidental nos impõe como totalidade. O segundo des-pensamento é o de que nenhuma teoria geral pode captar a diversidade do mundo, pois são infinitos os saberes que circulam nele, e a maioria da população do planeta gera a sua vida no dia a dia, seguindo preceitos e saberes que divergem e não cabem no saber científico [que se arroga ser rigoroso porque, pensado metodologicamente, é válido universalmente]. O terceiro des-pensamento é o de que não precisamos de alternativas, mas de um pensamento alternativo de alternativas, de atitudes plurais que visem reconhecer e valorizar experiências que se configurem como soluções para os problemas que afligem a vida individual e coletiva. O ato de des-pensar, que passa por um pensamento alternativo de alternativas, implica epistemologias do Sul, implica um cosmopolitismo com os sentidos do Sul. 


\section{REFERÊNCIAS}

SANTOS, Boaventura de Sousa \& MENEZES, Maria de Paula [Orgs.] Epistemologias do Sul. Cortez Editora, São Paulo, 2010.

SANTOS, Boaventura de Sousa. Por uma concepção multicultural de Direitos Humanos. Lua Nova, n. 39, p.105-124, CEDEC, São Paulo, 1997. . Pela Mão de Alice: o social e o político na pós-modernidade. Cortez Editora, São Paulo, 1995. 